\title{
Vertical Sunshine Temperature Gradient Loads Comparative Study
}

\section{ZHU Guang-xing}

\author{
School of Civil Engineering, Baicheng Normal University, Jilin, Baicheng 137000, China; \\ 935500969@qq.com
}

Keywords: Concrete box girder; field observation; temperature gradient load; temperature stress

\begin{abstract}
Under sunshine action the concrete box girder will generate temperature gradient load which will lead the temperature stress in the structure. But the sunshine temperature gradient load type and value for concrete structure are slightly different in specifications worldwide. Long-term Observe the sunshine temperature gradient load for a concrete box girder located in central china. Analyze the temperature gradient load observed and stipulated by codes worldwide. Results show, there is certain difference between values and types of sunshine temperature gradient load stipulated by specification of each nation. Suggested that, the temperature gradient standard value of concrete box girder should be different fetch according the characteristics of regions and climate.
\end{abstract}

\section{Introduction}

For a time in the concrete structure, each point temperature status of structure internal and surface are the temperature distribution. In concrete structure, due to coefficient of conduction for concrete is small, when the external environment temperature changes sharply, the change for internal temperature has distinct hysteresis. That phenomenon lead the bigger difference of heat each layer of concrete obtained or diffused and form temperature nonlinear distribution state. The temperature stress in the concrete lead the concrete bridge crack or serious accident at home and abroad since the 1960s, Friz Leonhardt has mentioned that, the temperature difference between the surface and bottom in the box bridge and beam bridge can achieve 27 to $33{ }^{\circ} \mathrm{C}$ which can lead the most prestressed concrete box girder damage. Therefore, the most adverse temperature distribution is the key for study the temperature effect on the concrete bridge.

\section{UK BS5400 Design Specification}

The regulation about temperature loads in the British BS5400 is the most detailed one for temperature loads of bridge at home and abroad so far. The daily and seasonal change such as air temperature, solar radiation, inverse radiation, have been considered in the general provision. For the top deck of box girder, Heating temperature distribution along the vertical beam direction stipulated by the BS5400 regulations shows in Fig.1

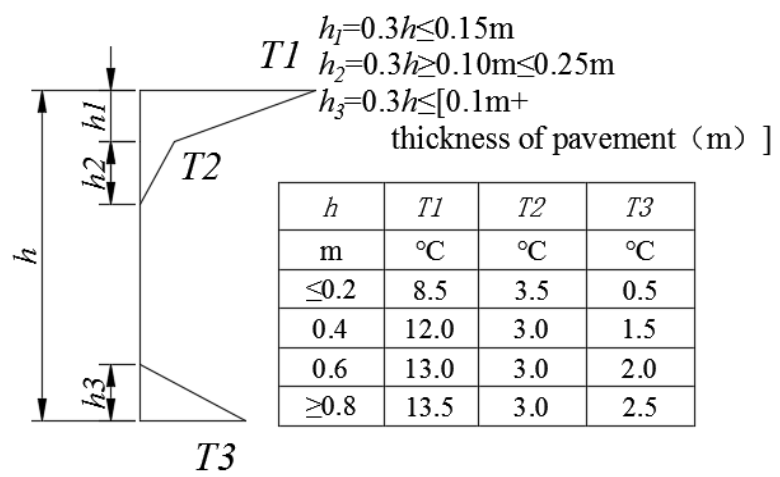

Fig.1 British BS5400 warming

For the top deck of box girder, cooling temperature distribution along the vertical beam direction stipulated by the BS5400 regulations shows in Fig.2. 


$h 1=h 4=0.2 \mathrm{~h} \leq 0.25 \mathrm{~m}$
$h 2=h 3=0.25 \mathrm{~h} \leq 0.2 \mathrm{~m}$
\begin{tabular}{|c|c|c|c|c|}
\hline $\mathrm{h}$ & $\mathrm{T} 1$ & $\mathrm{~T} 2$ & $\mathrm{~T} 3$ & $\mathrm{~T} 4$ \\
\hline $\mathrm{m}$ & ${ }^{\circ} \mathrm{C}$ & ${ }^{\circ} \mathrm{C}$ & ${ }^{\circ} \mathrm{C}$ & ${ }^{\circ} \mathrm{C}$ \\
\hline$\leq 0.2$ & 2.0 & 0.5 & 0.5 & 1.5 \\
\hline 0.4 & 4.5 & 1.4 & 1.0 & 3.5 \\
\hline 0.6 & 6.5 & 1.8 & 1.5 & 5.0 \\
\hline 0.8 & 7.6 & 1.7 & 1.5 & 6.0 \\
\hline 1.0 & 8.0 & 1.5 & 1.5 & 6.3 \\
\hline$\geq 1.5$ & 8.4 & 0.5 & 1.0 & 6.5 \\
\hline
\end{tabular}

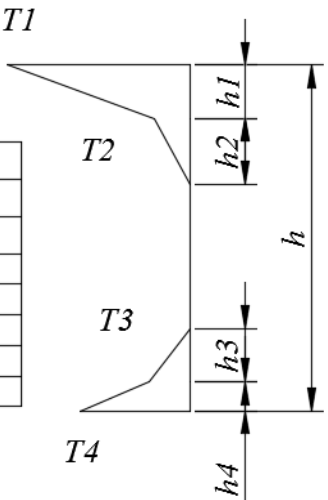

Fig.2 British BS5400 cooling

\section{AASHTO Design Specification}

For the temperature gradient, the vertical temperature gradient stipulated by latest AASHTO design code for highway bridge shown in Fig.3. The size $A$ in the Fig. 3 value as following. $A$ is $0.3 \mathrm{~m}$ for upper concrete structure while the height of beam greater than or equal to $0.4 \mathrm{~m}$, A is $-0.3 \mathrm{~m}$ for upper concrete structure while the height of beam less than $0.4 \mathrm{~m}, A$ is $0.3 \mathrm{~m}$ for steel girder bridge upper structure. Where, $T$ is thickness of concrete bridge deck. In order determine the temperature difference base of $T_{1}$ and $T_{2}$ shown in the picture, divided the homeland into four sun radiation zone. 1, 2, 3 areas mainly are in the western, central, eastern regions, 4 area is Alaska. The temperature base value for each region are shown in Table 1 . Where, $T_{3}$ generally is 0 or can be determine through specific research which cannot larger than $3{ }^{\circ} \mathrm{C}$.

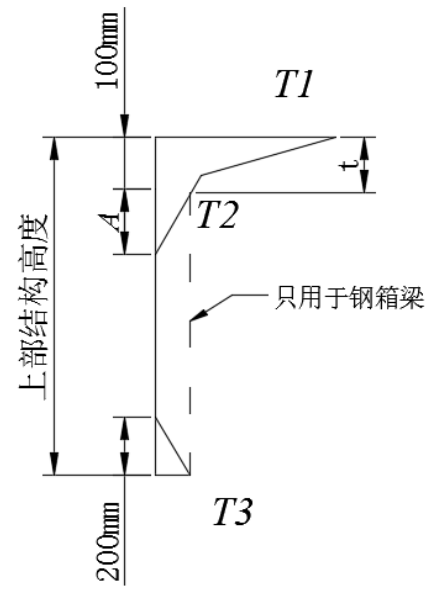

\begin{tabular}{|c|c|c|}
\hline 分区 & $T 1$ & $T 2$ \\
\hline 1 & 30 & 7.8 \\
\hline 2 & 25 & 6.7 \\
\hline 3 & 23 & 6 \\
\hline 4 & 21 & 5 \\
\hline
\end{tabular}

Fig.3 AASHTO

The vertical negative temperature gradient rules given below. For ordinary concrete bridge deck pavement, the data listed in the Table 3 times -0.3 , for asphalt concrete bridge deck pavement, the data listed in the table 3 times -0.2 .

\section{China Railroad Bridge Design Specification}

For a ballast box girder, it only considers temperature load along lateral direction. For the ballastless and no-bolster box girder, it should respectively consider the temperature difference load along the vertical direction and the temperature difference load along two directions.

Temperature difference load distribution in the box girder shown in Fig.4. Where, the temperature curve along the lateral and vertical are exponential functions which are calculated according the following formula. 


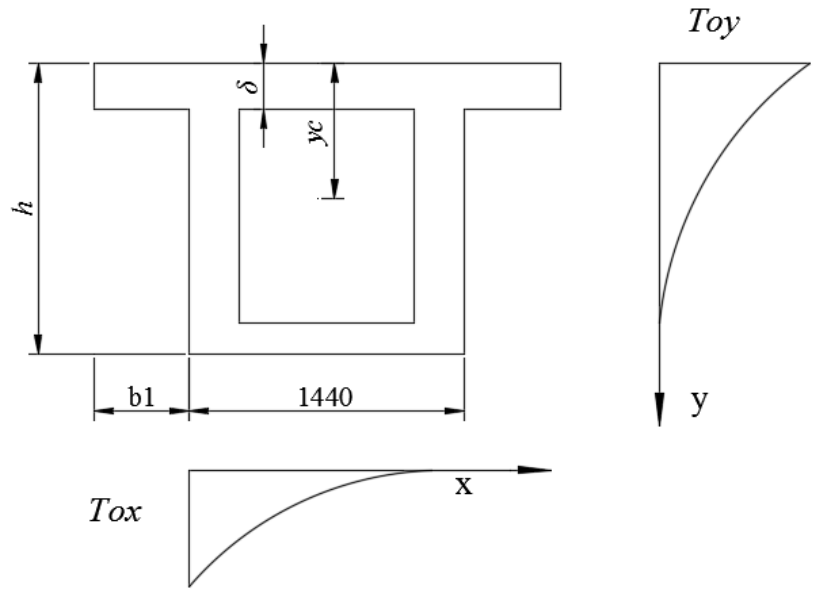

Fig.4 China Railway bridge standard

$\left\{\begin{array}{l}T_{x}=T_{o 2} e^{-a x} \\ T_{y}=T_{o 1} e^{-a y}\end{array}\right.$

Where, $T_{\mathrm{y}}$ and $T_{x}$ are the temperature difference in the computing point $y$ and $x\left({ }^{\circ} \mathrm{C}\right), T_{01}$ and $T_{02}$ are the temperature difference along the lateral and vertical direction of box girder, and fetch the values from the table 1 according to the design standard, $\mathrm{y}$ and $\mathrm{x}$ are the distance from the calculation points to the box girder surface, a fetched from Table 1.

Tab.1Sunshine Temperature curve of $a$ and $T_{0}$ value

\begin{tabular}{|c|c|c|c|c|c|c|}
\hline \multirow{2}{*}{\multicolumn{2}{|c|}{ direction type }} & \multicolumn{2}{|c|}{ Ballasted track } & \multirow{2}{*}{ direction } & \multicolumn{2}{|c|}{ Ballastless track } \\
\hline & & $a\left(m^{-1}\right)$ & $\mathrm{T}_{0}\left({ }^{\circ} \mathrm{C}\right)$ & & $\mathrm{a}\left(\mathrm{m}^{-1}\right)$ & $\mathrm{T}_{0}\left({ }^{\circ} \mathrm{C}\right)$ \\
\hline Along vertical & undirectional & 5 & 20 & \multirow{2}{*}{ Along lateral } & \multirow{2}{*}{7} & \multirow{2}{*}{10} \\
\hline & bidirectional & 7 & 16 & & & \\
\hline
\end{tabular}

The temperature difference curve along the thickness direction shown in Fig.5 can be calculated according the following formula.

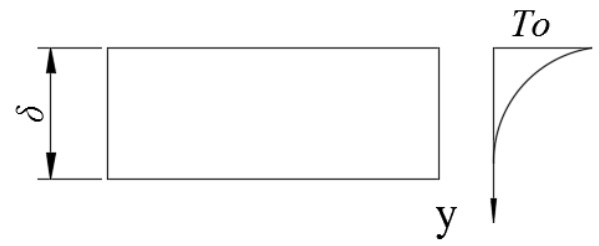

Fig.5 Temperature difference

$\left\{\begin{array}{l}T_{y}^{\prime}=T_{o 1}^{\prime} e^{-a^{\prime} y} \\ T_{y}^{\prime}=T_{o}\left(1-e^{-a \delta}\right)\end{array}\right.$

Where, $\delta$ is the thickness of plate $(\mathrm{m}), a$ fetched from table $2\left(\mathrm{~m}^{-1}\right)$.

For cooling temperature difference, the index of temperature difference curve along thickness of box girder top and web is 14 and corresponding $\mathrm{T}_{0}$ is $-10^{\circ} \mathrm{C}$.

Tab.2 Along the thickness temperature difference curve a`value

\begin{tabular}{cccccc}
\hline Thickness $\delta(\mathrm{m})$ & 0.16 & 0.18 & 0.20 & 0.24 & $\geq 0.26$ \\
\hline$a^{\prime}$ & 15 & 14 & 13 & 11 & 10 \\
\hline
\end{tabular}

\section{China Highway Bridge Design Specifications}

When calculating the effect temperature gradient load on the bridge, the vertical temperature gradient curve shown in Fig. 6 can be used. Where, the highest temperature $T_{1}$ of bridge deck are stipulated in the Table 3. When the height of concrete beam less than $400 \mathrm{~mm}, A=H-100(\mathrm{~mm})$, when the height of concrete beam greater than or equal to $400 \mathrm{~mm}, A=300$. For the steel structure with the concrete bridge deck $A=300 \mathrm{~mm}$, and $\mathrm{t}$ is the thickness of concrete bridge deck (mm). 


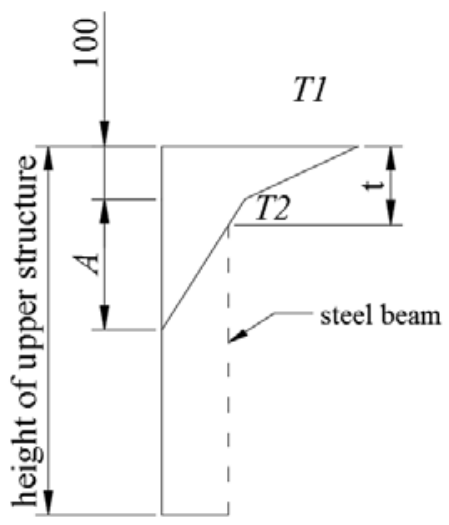

Fig.6 China highway standard

For the concrete upper structure and the steel structure with concrete bridge deck, the vertical sunshine negative temperature difference is 0.5 times positive temperature difference.

Tab.3 Vertical sunshine is the temperature difference between the calculated temperature base

\begin{tabular}{ccc}
\hline Structure type & $\mathrm{T} 1\left({ }^{\circ} \mathrm{C}\right)$ & $\mathrm{T} 2\left({ }^{\circ} \mathrm{C}\right)$ \\
\hline Cement concrete pavement & 25 & 6.7 \\
Asphalt concrete pavement $(50 \mathrm{~mm})$ & 20 & 6.7 \\
Asphalt concrete pavement $(100 \mathrm{~mm})$ & 14 & 5.5 \\
\hline
\end{tabular}

\section{Measured Maximum Positive and Negative Temperature Difference Curve}

Observation Method. Under the sunshine action, field observation the temperature field of bridge is a reliable method to analyze the law of temperature field on the bridge surface change with time and distribution type. Based on a actual bridge structure, long-term observe the surface temperature field and summarized the variation rule with time and distribution in space.

In this paper, the prestressed concrete continuous rigid frame box girder bridge is researched and the standard cross-section shown in Fig.7. The bridge is east-west direction, the calculation span of bridge is $45 \mathrm{~m}+70 \mathrm{~m}+45 \mathrm{~m}$. It is two parallel bridge and the observation object is the right bridge. Mainly use FLUKE TI25 thermal imager to observe the temperature field in summer, autumn, winter three seasons. Based on a quarter span section, analyze the internal and external surface temperature characteristics and change rule of season and daily. Study the change rule of internal and external surface temperature with time and distribution characteristics for prestressed concrete box girder. The observation temperature picture which has been processed shown in Fig.8.

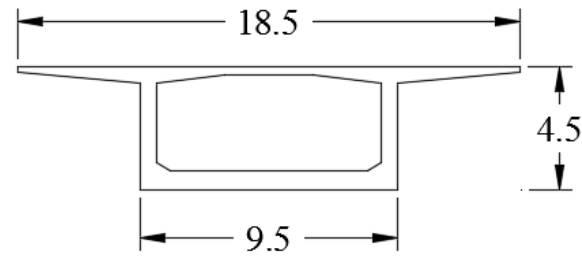

Fig.7 main span cross section profile (unit: $\mathrm{m}$ )

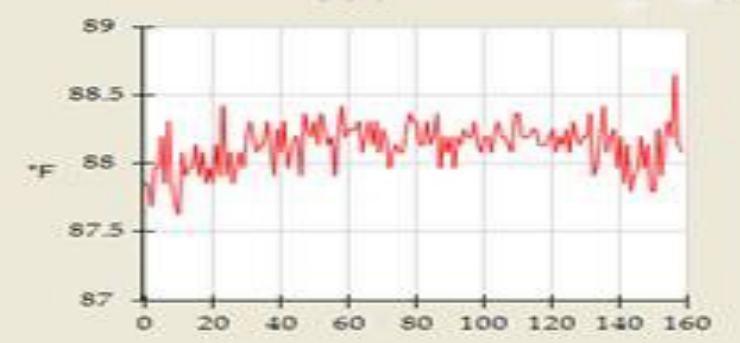

Fig.8 Thermal imager temperature value

Temperature Gradient Comparing. The maximum positive temperature difference curve observed list only for the quarter span cross section and compare the vertical temperature gradient curve observed with stipulated by the codes of foreign countries. Because of the measurement data 
belong the inner and exterior surface of box girder, here respectively average the absolute temperature of internal and external surface for the left and right web of box girder cross section, then minus the minimum value. If based on the $10{ }^{\circ} \mathrm{C}$ when bridge closure and $28.1^{\circ} \mathrm{C}$ when bridge temperature overall heat, the measured vertical gradient curves shown in Fig.9. The contrast of positive temperature difference load obtain conclusions as follows.

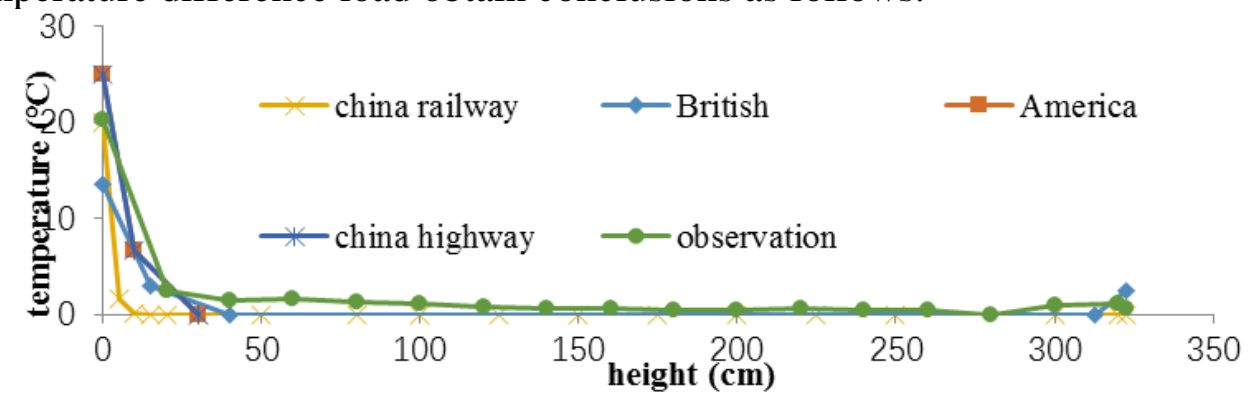

Fig.9 Sunshine temperature rising load comparing between each nation bridge standard and measuring

The positive temperature gradient line stipulated by British BS5400, American AASHTO, China's design code for highway bridge are most multi-segment bent. The positive temperature gradient line stipulated by China design code for railway bridge and observed are curve type.

For the positive temperature gradient load standard values which is the value of temperature gradient load on the roof, the value In the AASHTO specification is maximum, British BS5400 specification is minimum, the observed value in this paper is close to the value stipulated by china specification for railway bridge.

In this paper, the observed positive temperature gradient load value within the scope $40 \mathrm{~cm}$ from roof fast decrease. The drop rate is less than china railway bridge design specification but similar with China highway bridge design specification and AASHTO specifications.

There is a positive temperature difference in the bottom deck for UK BS5400 specification and AASHTO specification, but that is not stipulated by china railway bridge design specification and china highway bridge design specification. In this paper, the $1.2^{\circ} \mathrm{C}$ positive temperature difference observed in the bottom flange.

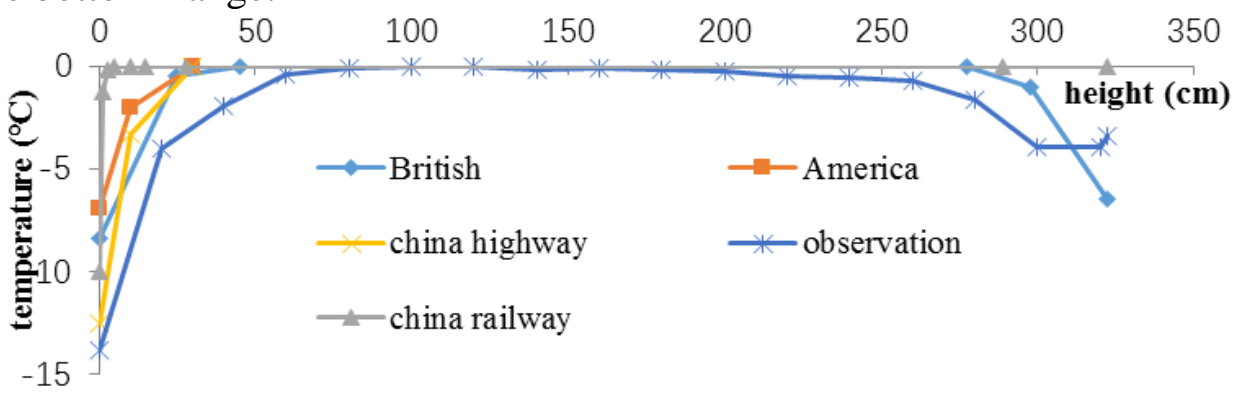

Fig.10 Cooling temperature difference load stipulated in codes worldwide comparing with measured

Based on the quarter span cross section observe the maximum vertical negative temperature gradient curve. The data prosecco method is the same with the positive temperature gradient curve. If based on the $10{ }^{\circ} \mathrm{C}$ when bridge closure and $-9.5^{\circ} \mathrm{C}$ when bridge temperature overall cool, the measured negative vertical gradient curves shown in Fig.10. Through the comparison of negative temperature gradient curve, some conclusions can be get as follows.

The negative temperature gradient line stipulated by British BS5400, American AASHTO, China highway bridge design codes are most multi-segment bent. The negative temperature gradient line stipulated by China design code for railway bridge and observed are curve type.

For the temperature gradient load standard values which is the value of temperature gradient load on the roof, the value observed is maximum, the value stipulated by the AASHTO specification is minimum.

In this paper, the observed negative temperature gradient load value within the scope $60 \mathrm{~cm}$ from roof fast increase and then inclines to stable value. the drop rate of temperature curve observed is less than stipulated by coeds. worldwide.

There is a negative temperature difference in the bottom deck for UK BS5400 specification and 
AASHTO specification, but that is not stipulated by china railway bridge design specification and china highway bridge design specification. In this paper, the $4{ }^{\circ} \mathrm{C}$ negative temperature difference observed in the bottom flange.

\section{Conclusion}

The positive and negative temperature gradient line type. line stipulated by British BS5400, American AASHTO, China's design code for highway bridge are most multi-segment bent. line stipulated by China design code for railway bridge and observed are curve type. so, curve type for temperature gradient line is suggested.

Temperature gradient load standard values. the value of temperature gradient load on the roof should fetch different according the different geographical climate.

Temperature difference load in bottom plate. There is a positive temperature difference in the bottom deck for UK BS5400 specification and AASHTO specification, but that is not for china railway bridge design specification and china highway bridge design specification. In this paper, temperature difference observed in the bottom flange. So, the existence of the temperature gradient load in the bottom plate is suggested considering.

\section{References}

[1]TB 10002.3-2005.Railway Bridges Reinforced Concrete and Prestressed Concrete Structure Design Code.

[2]BS5400,Steel,Concrete and Composite Bridges, Part2:1978-Specifications for Loads. British Standards Institute,1978.

[3]EN1991-1-5-2003,Eurocodel:Actions on structures-Part 1-5: General actions-Thermal actions. European Committee of Standardization,2003.

[4]New Zealand Ministry of Works and Development, Office of Chief Civil Design Engineer. Highway Bridge Design Brief, Issue C. New Zealand,1973.

[5]American Association of State Highway and Transportation Officials. AASHTO LRFD Bridge Design Specifications, SI Units, Third Edition,2004.

[6] JTJ D60-2004. Highway Bridge design general specification.

[7]JTJ D62-2004. Highway reinforced concrete and prestressed concrete bridge design code. 